\title{
A dimensão política da Transposição didática sobre a análise linguística em documentos parametrizadores para o Ensino Médio: o estudo do apagamento ${ }^{1}$ \\ The political dimension of didactic transposition over linguistic analysis in parametrizing documents to secondary school: the study of deletion
}

\begin{tabular}{|c|c|}
\hline $\begin{array}{l}\text { RESUMO: Este trabalho integra-se a uma } \\
\text { pesquisa mais ampla, na qual as dimensões } \\
\text { política, pedagógica e linguística da } \\
\text { Transposição didática foram investigadas a } \\
\text { partir de uma pesquisa documental de } \\
\text { inspiração qualitativa, baseada perspectiva de } \\
\text { uma Linguística Aplicada indisciplinar e } \\
\text { crítico-colaborativa (MOITA LOPES, 2003, } \\
\text { 2013). Neste artigo, temos como objetivo } \\
\text { apresentar a dimensão política do processo e } \\
\text { Transposição didática da proposta de análise } \\
\text { linguística, sugerida por João Wanderley } \\
\text { Geraldi na década de 80 do século XX, em } \\
\text { dois documentos parametrizadores do ensino } \\
\text { médio, a saber: Orientações Curriculares para } \\
\text { o Ensino Médio (BRASIL, 2006) e } \\
\text { Referenciais Curriculares para o Estado da } \\
\text { Paraíba (PARAÍBA, 2007). Os principais } \\
\text { subsídios teóricos são os conceitos de } \\
\text { Transposição Didática (CHEVALLARD, } \\
\text { 1991; RAFAEL, 2001; LEITE, 2007) e } \\
\text { Recontextualização Didática (BERNSTEIN, } \\
\text { 1996; MAINARDES E STREMEL, 2010; } \\
\text { LEITE, 2007). Para o estudo do objeto } \\
\text { específico - Análise Linguística - fizemos } \\
\text { uma revisão bibliográfica nos trabalhos de } \\
\text { GERALDI (1984, 1991, 1996) e de outros } \\
\text { autores. Os resultados nos levaram a concluir } \\
\text { que dimensão política da análise linguística se } \\
\text { faz através da despersonalização do autor, } \\
\text { demonstrada nos documentos } \\
\text { parametrizadores pelo apagamento da fonte } \\
\text { primária de referência e da pulverização das }\end{array}$ & $\begin{array}{l}\text { ABSTRACT: This work is part of a wider } \\
\text { research, in which the political, educational } \\
\text { and linguistic dimensions regarding didactic } \\
\text { transposition were investigated through a } \\
\text { documentary research of qualitative nature, } \\
\text { based on the prospect of an Applied } \\
\text { Linguistics which is both unruling and } \\
\text { critical-collaborative (MOITA LOPES, 2003, } \\
\text { 2013). In this article, we attempt to present the } \\
\text { political dimension of the process and the } \\
\text { didactic transposition of the proposed } \\
\text { linguistic analysis, suggested by John } \\
\text { Wanderley Geraldi in the 80s, in two } \\
\text { parameterizing secondary school documents, } \\
\text { namely: Curriculum Guidelines for Secondary } \\
\text { Education (BRAZIL, 2006) and Curriculum } \\
\text { References for the State of Paraíba } \\
\text { (PARAÍBA, 2006). The main theoretical } \\
\text { elements are the concepts of Didactic } \\
\text { Transposition (CHEVALLARD, 1991; } \\
\text { RAFAEL, 2001; LEITE, 2007) and the } \\
\text { Recontextualizaton of Didactics } \\
\text { (BERNSTEIN, 1996; MAINARDES And } \\
\text { STREMEL, 2010; LEITE, 2007). For } \\
\text { studying the specific object - Linguistic } \\
\text { Analysis - we did a literature review on the } \\
\text { works of GERALDI (1984, 1991, 1996) and } \\
\text { other authors. The results led us to conclude } \\
\text { that the political dimension of linguistic } \\
\text { analysis is done through the depersonalization } \\
\text { of the author, as demonstrated in the } \\
\text { parameterizing documents, by erasing the } \\
\text { primary reference source and the }\end{array}$ \\
\hline
\end{tabular}

${ }^{1}$ Este artigo foi produzido a partir da pesquisa de mestrado materializada na dissertação "Da proposição à oficialização: a didatização da análise linguística em documentos parametrizadores para o Ensino Médio" defendida no Pósle, em agosto de 2015.

*Unidade Acadêmica de Letras, UFCG. deniselinoaraujo@gmail.com

** UFCG. isaguedessilva@gmail.com 
fontes de consulta. Esse processo que inclui a seleção, a organização e a divulgação do conceito da proposta de ensino de Análise Linguística leva à exaltação do Estado, como se esse fosse o autor de tal proposta. Como implicação direta desse resultado, verificamos nos documentos o desvelamento das relações de classificação (poder) e enfraquecimento (controle) do Estado sobre o tema focalizado.

PALAVRAS-CHAVE: Transposição Didática. Análise Linguística. Política. Ensino de língua materna. pulverization of information sources. This process of selecting, organizing and disseminating the concept towards the teaching of Linguistic Analysis results in the State's exaltation, as if it was the author of such a proposal. As a direct implication of this result, we noted in the documents the unveiling of the State's relations of classification (power) and weakening (control), in the theme in focus.

KEYWORDS: Didactic Transposition. Linguistic Analysis. Policy. Mother tongue teaching.

\section{Introdução}

A Análise Linguística (doravante AL), conceito e proposta metodológica para o ensino de língua materna elaborada e difundida por João Warderley Geraldi, na década de 80, do século XX, surge para ressignificar o ensino de gramática realizado, até então, de modo metalinguístico, através da descrição de compoenentes linguísticos, da memorização de regras e de exercícios mecânicos e descontextualizados.

Essa proposta emerge em meio a transformações políticas, sociais e culturais intensas, quando se dava no Brasil o processo de abertura política e a redação da nova constituição, portanto, em meio a um ambiente político no qual as demandas populares tendiam ser respeitadas e atendidas. Nesse contexto, pensava-se numa reforma educacional que pudesse, enfim, colocar na escola os filhos das camadas populares dando-lhes condições reais de aprendizagem e desenvolvimento. Um dos focos dessa reforma era um ensino de língua que pudesse fazer esses alunos, historicamente excluídos, participar da vida social em condições de igualdade por conhecer a sua variante linguística de origem e a de prestígio, sabendo utilizá-las com própositos definidos.

Em paralelo, do ponto de vista global, organizava-se mais fortemente uma política neoliberal que influenciou decisivamente as decisões políticas na década seguinte, em cujo âmbito veio a público o documento Parâmetros Curriculares Nacionais para o Ensino Fundamental: Língua Portuguesa (BRASIL, 1998) (doravente PCNLP), que não apenas incorporou o conceito de AL como o divulgou, dando-lhe um caráter de expressão de um novo paradigma de ensino. 
A AL surge, no âmbito acadêmico, como uma alternativa inovadora para o ensino, definida pelos preceitos de Geraldi ([1984] 2006) como uma prática de análise da língua em uso, através da qual é possível refletir sobre seus aspectos discursivos, estilísticos, gramaticais, etc. Essa reflexão, segundo o autor, deve ser conduzida e sistematizada pelo professor e utilizada como recurso norteador da produção do texto do aluno.

Essa proposição ganhou força não só junto a estudiosos, sobretudo os vinculados aos estudos enunciativos e interacionistas, como também junto às diversas iniciativas de formação de professores, inicialmente, cursos isolados, como os que deram origem ao livro O texto na Sala de Aula (GERALDI, [1984] 2006), repositório da primeira versão dessa proposta metodológica e conceitual que, depois, foi assimilada em documentos oficiais de diversos estados brasileiros e, no final da década seguinte, atingiu um ápice ao ser incorporada pelo PCNLP, que lhe deu, assim, um caráter de oficialização.

Inserida nesse documento, essa proposta foi levada a todo o Brasil incentivando uma reformulação teórica e metodológica da ação docente, muito embora fosse vista pela grande maioria dos professores como absolutamente desconhecida. Isto gerou uma "corrida" acadêmica por parte de vários pesquisadores tanto para explicá-la como para demonstrar como utilizá-la em sala de aula, conforme descrito em Souza (2015).

Tal como ocorreu com o fundamental, deu-se o mesmo como ensino médio (EM), pois, na primeira década do século XXI, os documentos parametrizadores destinados a subsidiar a ação docente na etapa final da educação básica passaram a apresentar a AL como um conceito e uma metodologia de ensino. Dentre esses, destacamos as Orientações Curriculares do Ensino Médio (BRASIL, 2006) - OCEM - e os Referências Curriculares para o Ensino Médio da Paraíba (PARAÍBA, 2007) - RCEM-PB - que são, respectivamente, um documento do âmbito federal e outro do estadual

Contudo, após três décadas da proposição inicial feita por Geraldi [(1984) 2006), de diversas pesquisas sobre o tema e dos esforços de investigadores, bem como do governo em apresentar a AL nos documentos oficiais, pouco ainda se sabe sobre o processo de Transposição didática (TD) desse objeto de estudo acadêmico em objeto de ensino em documentos parametrizadores. Em pesquisa mais ampla (SOUSA 2015), verificamos que esse processo se faz em três dimensões, a saber: política, pedagógica e linguística. Neste artigo, objetivamos demonstrar como essa primeira dimensão se mostra através da despersonalização do autor, materializada pelos recursos linguísticos do apagamento da fonte de referência primária 
(Geraldi [1984] 2006, [1991], 2003) e da pulverização das fontes de consulta no corpus analisado que são os documentos parametrizadores supracitados.

Este artigo está organizado em quatro partes. A primeira é esta introdução; a segunda situa os fundamentos teóricos; a terceira traz os pressupostos metodológicos e os resultados; e a última as considerações finais, seguida das referências.

\section{A ação de didatização em documentos parametrizadores: origem, conceito e procedimentos}

Nosso objeto de investigação é a AL, tal como definida por Geraldi ([1991] 2003, p. 190). Esse autor a entende como um conjunto de atividades que tomam a reflexibilidade como objeto de estudo. Essa é uma das características da linguagem e que permite ao sujeito falar sobre si e sobre o mundo, mas também sobre a própria linguagem, de modo consciente, objetivando usar os recursos expressivos em função da atiyidade linguística em que está engajado.

Segundo esse autor, a proposta metodológica da AL toma a produção de textos como o princípio do processo ensino/aprendizagem. A justificativa para isso está no fato de que os discursos são a materialização da língua(gem) em textos. Outra característica peculiar da proposta de Geraldi que deve ser enfatizada é seu propósito relativo ao ensino das unidades linguísticas, vistas por um percurso metodológico diferente e pela adoção de uma postura teórica distinta daquela na qual se pauta o ensino de gramática. Essa proposta não pretende ser uma substituição desse ensino, mas uma etapa de sua execução, que não era (e continua sendo, na maioria dos casos,) realizada através de um ensino transmissivo de língua, conforme afirma o autor:

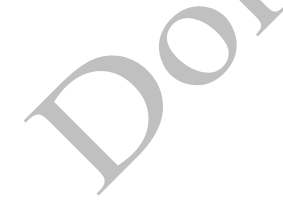

Historicamente, o ensino escolar da gramática não visou a construção de uma teoria sobre a língua, mas a aprendizagem de uma descrição da língua eivada de normalizações. E mais ainda: esta descrição nunca ultrapassou a classificação, qualquer que seja o nível descrito. As gramáticas escolares, todas inspiradas na gramática tradicional, vão muito pouco além das classificações (há mais ou menos dois séculos, fazer ciência era classificar objetos e processos, e hoje a ciência está longe de ser meramente taxonômica). (GERALDI, 2010, p.184).

Portanto, essa proposta não pretende excluir o ensino de gramática ou atribuir simplesmente uma nova nomenclatura a uma prática consolidada, mas visa refletir sobre os 
recursos expressivos, descrevê-los e sistematizar os conhecimentos sobre os mesmos, como uma sequência de etapas interconectadas e atravessadas por novas concepções para construção do conhecimento. Nessa proposta, o movimento e o funcionamento do ensino/aprendizagem não devem ser lineares nem unilaterais.

As características mais singulares da proposta aqui referida podem ser sumarizadas do seguinte modo: texto do aluno é ponto de partida e do chegada do trabalho, pois o fundamento básico é a língua em uso. Num primeiro momento, considerava-se somente o material produzido pelos alunos (GERALDI, [1984] 2003) como fonte de dados para reflexão sobre a linguagem. Os textos escritos por outros autores eram objeto de leitura, mas não de apreciação da engenharia textual. Somente depois essa possibilidade foi incorporada pelos continuadores da proposta. Com base no material produzido por cada série e turma, o professor deveria (deve) identificar os problemas linguísticos (ortográficos, morfossintáticos, fonológicos) mais recorrentes, que deveriam (devem) ser abordados a partir da atividade de reescrita do texto. A crença fundamental era (é) a de que alunos criariam uma consciência linguística que os auxiliaria a (re)escrever seus próprios textos em língua padrão a partir do estudo sistematizados dos “erros" nos usos linguísticos. Posteriormente, no livro Portos de Passagem [(1991) 2003], o autor passa a incluir o estudo sistemático das operações discursivas entre as preocupações com o ensino da língua.

A singularidade da proposta está em inverter o direcionamento clássico que vai do conceito ao exemplo, adotando a postura da reflexão sobre o uso dos recursos linguísticos como procedimento necessariamente anterior à sistematização/descrição da língua. Assim, a sequência de atividades deve seguir um crescendo, sendo iniciada como as atividades linguísticas, seguidas das epilinguísticas e finalizadas com as metalinguísticas.

Essa proposta supõe, por conseguinte, um trabalho customizado. E justamente essa característica uma das que rendeu a crítica mais recorrente em face da proletarização do trabalho do professor que o impede de dedicar-se integramente a cada turma tal como suposto. Outra crítica focalizou aspectos políticos da proposta, designando-a de uma proposta para os "pobres", pois visava empodeirar aqueles que não usavam a variante de prestígio, dotando-os de conhecimentos linguísticos sobre essa variante para se afirmarem no mundo da cidadania. Isto não era bem visto pelosos críticos que diziam ser essa proposta uma reafirmação da barreira linguística existente entre ricos e pobres no Brasil, pois, os primeiros não precisariam estudar língua na escola, já os segundos deveriam dedicar grande tempo para isso. Outras críticas se 
voltavam para a formação docente, apontando-a como a vilã do processo, pois, gerações de docentes haviam sido formadas na base da memorização de conceitos sobre a língua e com poucas experiências de escrita, o que as impedia, inicialmente, de adotar uma proposta como essa que supõe um professor capaz de descrever e explicar fenômenos linguísticos, inclusive, a partir de sua própria experiência como produtor de textos.

De modo geral, foram essas as críticas. Ficaram no terreno da retóerica e não conseguiram demover a proposta que segue até hoje como seminal, visto que não houve outra proposta com tão grande repercussão. Além disso, seu cerne é a prática letrada da produção de textos por parte dos alunos e, nesse sentido, articula-se com as diversas teorias educacionais e psicológicas que defendem a aprendizagem como prática de interrelação com o objeto de aprendizagem.

Nas subseções a seguir, vamos sumarizar os aspetos fundamentais da teoria francesa de Transposição didática e da anglo-saxã da Recontextualização didática, para, na próxima seção, demonstrarmos como esse objeto - AL - foi politicamente didatizado em documentos parametrizadores do ensino.

\subsection{Transposição Didática}

A Transposição Didática é definida como um "processo de transformações pelo qual passa um determinado saber em uma situação de exposição didática". De acordo com Chevallard (1991), essa teoria enfoca a epistemologia do saber, as mudanças e adaptações pelas quais este passa. Dentre as motivações que surgem para ocorrência de um movimento de TD, Petijean (2008), ao analisar o ensino de Língua francesa no século XX, destaca: (1) o aumento da responsabilidade social, (2) a superação do obsoletismo didático e (3) a diminuição do fracasso escolar.

Segundo esse autor, a TD acontece quando o distanciamento entre os saberes ensinados e os saberes eruditos/acadêmicos é tão grande que aqueles parecem inadequados ao ensino. Isso exige uma atualização que, não raro, surge em meio a uma crise interna da disciplina, que o sistema educacional procura solucionar com a mudança de saberes ou com sua atualização, afetando, por sua vez, as práticas docentes. Ou seja, quer tenha com objetivo solucionar um dos três problemas citados pelo pesquisador francês ou todos eles, o processo de TD afeta, primeiramente, as práticas docentes, pois, em nosso entendimento, sem que essas sejam alteradas ou modificadas não será possível atingir nenhum desses objetivos. 
Dos aspectos inerentes à TD que são essenciais para que o saber transposto se constitua como conhecimento escolar, destacamos: (1) a natureza do saber, (2) o perfil contextual para onde este saber vai ser transposto e (3) o contexto institucional das práticas de transmissão que o caracteriza. Tendo em vista esses aspectos, Rafael (2001) e Petijean (2008) destacam cinco procedimentos próprios dessa operação que transforma o saber acadêmico em saber escolar, são eles: a dessincretização, a despersonalização, a programabilidade, a publicidade e o controle.

A dessincretização diz respeito ao processo de recorte da teoria; pode ser entendida como a ação de retirar o saber de sua origem científica para transformá-lo em um saber passível de ensino, ou seja, significa transformar um objeto de estudo acadêmíco em objeto de ensino. Por exemplo, ao selecionar aspectos sobre AL que podem constituí-la enquanto um conhecimento escolar, deixa-se de lado outros aspectos que serão compreensíveis ou relevantes apenas na esfera acadêmica, como uma descrição linguística pormenorizada.

A despersonalização refere-se à separação entre o cíentista e o saber por ele proposto. É o saber desvinculado de seu campo de referência e de seu autor, mesmo que mantenha o nome e conceito do campo científico; diz respeito a perda de autoridade sobre o saber, ainda que seja do conhecimento de todos a quem pertence a autoria. Como se poderá confirmar com a análise dos dados, a AL torna-se um conhecimento que não mais é proposto não por Geraldi, mas por vários pesquisadores e pelo Estado, consequentemente, passa a ser um saber de domínio comum, sobre o qual autores de livros didáticos, professores e especialistas discorrem livremente sem a necessidade de remeter à fonte ou ao seu autor. Isso é diferente, por exemplo, das Leis de Newton ou da Teoria da Relatividade de Einstein ${ }^{2}$, que embora já dessincretizados mantêm a personalização. Referir-se a elas implica citar seus propositores.

A programabilidade, que é o terceiro procedimento listado pelos autores, diz respeito à reorganização do conhecimento desincretizado e despersonalizado, em sequências racionais para aquisição progressiva por parte dos alunos. Essa ação insere o saber em um programa de ensino, adequando-o ao tempo e a outros aspectos relevantes, de acordo com os objetivos propostos para o ensino. Em se tratando da AL, sabemos que ela se insere no programa de ensino de língua, enquanto metodologia para análise reflexiva para a produção textual (escrita e oral), a leitura, a reescrita, a e o estudo gramatical.

\footnotetext{
${ }^{2}$ Na nossa área, podemos citar os conceitos de Gênero de M. Bakhtin ou de C. Miller. Referir-se a esses conceitos implica citar os autores.
} 
A publicidade ou divulgação do saber é procedimento de inserção desse novo saber em um suporte e gênero capaz de lhe dar visibilidade. No âmbito de um movimento de TD, parecenos que não há melhor espaço para publicidade do que um texto oficial, mais especificamente um currículo, pois este, em geral, tem "força de lei”, carrega consigo a marca da inovação e da intenção de que é para o "bem de todos". Um texto oficial (currículo, portaria, instrução normativa etc) possibilita a divulgação e legitimação de um saber. No Brasil, a partir da década de 90 do século XX, temos uma vasta publicação sobre o tema AL nos Parâmetros Curriculares Nacionais, Diretrizes Curriculares Nacionais, Orientações Curriculares, além dos livros didáticos.

O controle (práticas de avaliação) diz respeito às ações de avaliação pelas quais passa o saber, a fim de que os agentes da Transposição avaliem se houve aprendizagem ou não. No caso da AL, são os professores - agentes da chamada TD interna - que avaliam através das práticas escolares (exercícios, provas, produções textuais) o uso da AL

Observando esses aspectos do processo de TD da AL para os documentos parametrizadores focalizados, verificamos que os dois primeiros são bem evidentes, dado que a AL foi dissociada de seu contexto acadêmico para ser (re)apresentada num outro, que é o do currículo proposto no âmbito das políticas públicas para educação. Essa dissociação levou à despersonalização, pois, Geraldi, que tem um papel importante na construção dessa metodologia de trabalho didático reflexivo com a língua é pouco citado, como mostrará a análise posteriormente. A programabilidade é uma característica intrínseca da AL, que supõe em sua gênese um trabalho customizado para cada turma, a ser pensado pelo docente. A essa característica está associada ao controle, ambas indissociavelmente ligadas. A publicidade, por sua vez, pode ser vista como parte da divulgação feita em torno dos documentos parametrizadores e das "ideias inovadoras" que eles traziam (trazem).

Posta essa sumarização da TD, passamos a apresentar a Recontextualização Didática.

\subsection{Recontextualização Didática}

O conceito de Recontextualização surge em 1971 e é ampliado em mais cinco publicações da obra Class, Codes and Control $^{3}$, nas quais Basil Bernstein aprimora a sua Teoria da Construção do Dispositivo Pedagógico. Esse modelo teórico se propõe a desvelar a

\footnotetext{
${ }^{3}$ Em 1975, 1981, 1986, 1999 e suas reedições.
} 
complexidade das práticas escolares, percebidas em permanente articulação com contextos sociais mais amplos. Conforme Mainardes e Stremel (2010), essa teoria foi elaborada como um modelo para analisar o processo pelo qual uma disciplina ou campo específico é transformado ou "pedagogizado" para constituir o conhecimento escolar, o currículo, os conteúdos e relações a serem transmitidas. (MAINARDES;STREMEL, 2010, p. 11)

Segundo Santos (2009), Bernstein acredita que o Poder cria categorias que se diferenciam entre instâncias, agentes, discursos ou práticas, delimitando posições e fronteiras. Além disso, afirma ainda que o controle social estabelece formas de comunicação para as categorias, definindo códigos específicos no interior dos grupos e entre um grupo outro. Poder e controle social são elementares nessa teoria, pois o autor criticou as teorias reprodutivistas por acreditar que se limitavam a uma visão determinista entre as práticas pedagógicas e seus contextos, assim,

...empenhou-se na criação de um modelo teórico que fornecesse "uma linguagem especial", capaz de recuperar as macrorrelações, a partir das microinterações, revelando como se conformam na prática, as relações de poder e controle, enquanto formas de comunicação. (LEITE, 2007, p. 23)

Dois conceitos são centrais nessa teoria - classificação e enquadramento. Classificação refere-se à relação de poder entre os agentes de produção dos discursos, pois quanto mais distante e hierarquizada for essa relação mais forte será a classificação do saber e mais preservada será a identidade dos produtores. Onde a classificação é forte, os conteúdos são distantes, como os conhecimentos disciplinares. Por exemplo, quanto mais forte a classificação do discurso educacional mais distante será do discurso de senso comum. Numa classificação fraca, conteúdos e áreas de estudo são mais próximos, como na perspectiva interdisciplinar de ensino. Para ilustrar, voltemos ao exemplo sobre as leis de Newton e a Teoria da Relatividade. A classificação de ambos é forte tanto porque não se misturam com os conhecimentos do senso comum, ainda que possam ser identificados entre estes, quanto porque ao ser apresentados na escola faz-se sempre referência aos seus produtores, ou seja, são conhecimentos datados e nomeados, cuja apresentação não dispensa esse ancoramento que passa de geração a geração de pesquisadores e docentes.

O enquadramento é o lado reverso e indissociável da classificação e refere-se ao controle do que é transmitido como o conhecimento disseminado nas interações comunicativas 
e também pode ser definido como forte ou fraco. Em um enquadramento forte, o transmissor é o regulador único e dominante do conteúdo. Em um enquadramento fraco, a responsabilidade entre os interlocutores é compartilhada e negociada, como ocorre, por exemplo, na perspectiva da pegadogia freirena na qual há negociação entre professor e aluno relativa a conteúdos, metodologias de ensino, tipo de atividades e formas de avaliações.

No âmbito dessa teoria, o processo de Recontextualização é entendido como transformador do discurso, pois atua em aspectos que o tornam singular no campo de produção, a saber: (1) o tempo, que tem uma referência especializada, tornando 0 discurso recontextualizado atemporal; (2) o corpus, pois os textos selecionados assumem o status de conteúdos escolares pela sua relevância; e (3) o espaço escolar em que é disseminado, pois assume classificação e enquadramento, forte ou fraco, dependendo de qual seja esse espaço e quem sejam os agentes envolvidos. Esse processo é realizado através de quatro etapas, que são seleção, simplificação, condensação e reelaboração.

A seleção é realizada pelos agentes recontextualizadores e diz respeito a uma triagem dos conhecimentos produzidos e que serão recontextualizados. De acordo com Leite (2007, p. 32), o perquisador inglês assume que o conhecimento a ser recontextualizado não advém necessariamente da academia, mas emerge de outros contextos do sistema educacional.

A simplificação é a etapa de minimização da complexidade do discurso considerado como real. O estudo inicial de Bernstein apresenta como exemplo a física que se ensina no espaço escolar comparada a física desenvolvida pelos físicos (em um contexto de produção intelectual): enquanto está no campo de produção intelectual, ou contexto primário como define o pesquisador, constitui um discurso real, em seu contexto de origem, incorporado por aspectos históricos, sociais, e por relações de poder desse contexto. Ao ser reposicionada, recontextualizada, passa por um processo de simplificação que minimiza a complexidade do discurso real.

A condensação é a etapa de reestruturação do conhecimento em que ele adquire nova organização quanto às informações e conceitos, em função do tempo, do lugar e dos sujeitos a que se destinam.

A reelaboração seria o novo discurso que se torna, nos termos do autor citado, um discurso "imaginário", assumindo outra lógica outros objetivos (educacionais), nova sequência e organização e novo ritmo. 
Nesse processo de Recontextualização, Bernstein acredita que há influência da ideologia (poder central) que age através de seus agentes recontextualizadores. Para esse autor, diferentemente de Chevallard, o saber que é didatizado não advém apenas do campo científico, mas de diferentes espaços de produção e reprodução, que são construídos e constituídos pelas relações de poder através de um discurso regulador. Nesse sentido, é que o autor da Teoria do Dispositivo Pedagógico assume que há, na Recontextualização, um campo recontextualizador oficial e um campo recontextualizador pedagógico, como se houvesse um "discurso oficial" e um "discurso da sala de aula".

Acreditamos que as etapas de Recontextualização dos saberes apontadas pelo pesquisador anglo-saxão podem ser de alguma forma relacionadas às indicadas pelo pesquisador francês. De modo geral, vemos uma relação entre ambas as teorias, com o destaque de que na versão da Recontextualização a dimensão política do processo de Transposição didática ganha relevo, enquanto na vertente da Transposição didática essa dimensão não é destacada entre as demais. Quanto às etapas e processos, acreditamos que as de simplificação e de reelaboração apontadas por Bernstein podem ser relacionadas ao processo de dessincretização apontado por Chevallard, pois o foco, em qualquer dessas descrições, é demonstrar a transformação sofrida por um saber quando sai do seu contexto de origem tendo em vista a esfera escolar. Por outro lado, a seleção e a condensação podem ser relacionadas à programabilidade, apontada pelos estudos desse último autor citado. Em ambos os casos, objetiva-se dosar o que pode e deve ser dito sobre um determinado saber, além de como e quando fazer isso na esfera escolar.

Nessa correlação de processos e etapas, verificamos que não há correspondência para a despersonalização, nem para o controle e a publicidade, processos que revelam opções políticas da Transposição didática, sobretudo para o primeiro desses, conforme demonstramos na análise.

\section{O percurso de pesquisa com documentos-monumentos em Linguística Aplicada}

A pesquisa aqui apresentada foi realizada à luz de uma abordagem qualitativa, perspectiva que tem como base a Fenomenologia Social, a Sociologia do Conhecimento e o Interacionismo Simbólico, os quais compreendam o seu objeto a partir de um olhar multilateral para construção de significados, entendidos pela subjetividade, pelas interações ditas complexas que redefiniram concepções positivistas vigentes na ciência, para essa vertente. 
Em outras palavras, os pesquisadores qualitativos pretendiam maximizar a validade de seus resultados, balizando ou explorando os recursos da subjetividade, mais do que tentando excluí-la dos processos de pesquisa; bem como incentivando uma análise dos fenômenos sociais no contexto natural, mais do que num contexto que se tentava neutralizar, de início, para chegar a nele estabelecer, rapidamente, generalizações. (LAPERRIÈRRE, 2012, p. 412).

Essa compreensão de pesquisa se coaduna com a perspectiva da Linguística Aplicada (doravante, LA) que iniciada, no Brasil, principalmente com os estudos de Maria Antonieta Alba Celani na década de 60, do século XX, assumiu distintas concepções, de natureza epistemológica e metodológica, dialogando com as diversas disciplinas como a Psicologia, a Sociologia, a Antropologia, a Neurolinguística, a Filosofia, a História, a Análise do Discurso, etc. para subsidiar a compreensão da heterogeneidade linguística. Esse campo de estudo é definido por Moita Lopes (2006) como indisciplinar, mestiço e ideológico, pois na modernidade recente não separa o conhecimento produzido a respeito de sujeitos deles próprios, ao mesmo tempo que permite-lhes estar próximo das visões/valores/ideologias do pesquisador, com análises subsidiadas por diversos campos do conhecimento e não mais em disciplinas especificas. A LA também se propõe crítico-colaborativa conforme situa Moita Lopes (2013, p.17).

A pesquisa na LA em seu desenvolvimento no Brasil o coloca [o sujeito] como crucial em sua subjetividade ou intersubjetividade, tornando-o inseparável do conhecimento produzido sobre ele mesmo, assim como das visões, valores e ideologias do próprio pesquisador. Em decorrência, questões de ética, poder e política se tornam inerentes a produção do conhecimento.

Dessa citação, entendemos que nos contextos de ensino investigados, a LA considera a produção do conhecimento como produto de demandas sociais, culturais e ideológicas, produzidas para responder às necessidades que emanam em um dado momento, para e por sujeitos específicos, caracterizando-se como singular e localmente situada. Por isso, é inseparável, especificamente é inerente, pois o sujeito produz e se constrói pelo conhecimento produzido. O investigador deve não apenas identificar e analisar, mas buscar a propositura de um retorno do conhecimento investigado/produzido aos contextos de investigação, na tentativa de colaborar para que haja a transformação qualitativa da realidade abordada.

Trazendo esse princípio para nossa investigação, entendemos que não basta apenas refletir sobre a AL, como uma proposta didática de transformação do ensino de língua, mas é 
preciso reconhecer que ainda temos muito a dizer quanto à aplicabilidade dessa proposta, se pensarmos na diversidade e heterogeneidade quanto à formação dos professores, na recepção dos alunos ao novo, na conciliação de uma identidade tradicional de professor com uma identidade de professor inovador.

Essa perspectiva, por envolver sujeitos em contextos situados, emanam questões de ética, poder e política, das quais o pesquisador de LA deve, não apenas criticar seus sujeitos/objetos de investigação, apontando o que é certo, errado ou adequado no ensino, mas colaborar para que os possíveis obstáculos que sejam encontrados, tanto na realidade analisada como entre os sujeitos possam ser superados ou transformados.

Assim, nosso objeto de investigação nos conduz a definir esta/pesquisa como de abordagem qualitativa, do tipo interpretativista (MOREIRA; CALEFFE, 2008). A pesquisa qualitativa preocupa-se com aspectos da realidade que não podem ser quantificados, centrandose na compreensão e explicação da dinâmica das relações sociais complexas, na qual interpretamos e atribuímos significados ao nosso corpus.

\section{A didatização da análise linguística em sua dimensão política: o recurso do apagamento}

Situando nossa pesquisa no âmbito de uma Linguística Aplicada que visa produzir inteligibilidades sobre contextos de uso da lingugem (Cf. MOITA LOPES, 2006), empreendemos uma análise dos dados documentais ${ }^{4}$ que constituem a pesquisa - Orientações Curriculares para o Ensino Médio (BRASIL, 2006) - OCEM - e Referênciais Curriculares para o Estado da Paraíba $(2007)^{5}$ - RCEM-PB - com vistas a identificar dimensões da Transposição/Recontextualização didática através de sua(s) manifestação(ões) linguística(s), uma vez no âmbito do paradigma interpretativista é na linguagem e através dela que ações se realizam.

Assim, foram identificadas três dimensões. Uma dimensão linguística da Transposição/Recontextualização didática, uma dimensão pedagógica e uma dimensão política. Neste artigo, optamos por divulgar essa última dimensão porque acreditamos é menos analisada no âmbito dos trabalhos sobre Transposição didática realizados no Brasil à luz da escola

\footnotetext{
${ }^{4}$ Os documentos foram analisados como Documentos/Monumentos, cf. Le Goff (1997).

${ }^{5}$ Cabe lembrar esse documento traz proposta curricular para as quatro macro áreas do ensino médio - Linguagens, Matemática, Ciências Humanas e Ciências da Natureza. Focalizamos apenas a proposição de AL no âmbito da área de ensino de língua materna.
} 
francesa (RAFAEL, 2001; SANTOS, 2009; entre outros) e também porque acreditamos que as escolhas feitas no âmbito dessa dimensão afetam o que se faz e o que se diz nas duas outras. Ademais, de acordo com Mainardes e Stremel (2010), não obstante as críticas, ainda há espaço para se aplicar a teoria da Recontextualização didática na análise de contextos educacionais. Em Linguística Aplicada são raros os estudos à luz dessa teoria e praticamente inexistente aqueles que a cojungam com a TD (LEITE, 2007), fato que nos motiva a construir uma leitura dos dados relacionando-as.

A fundamentação teórica nos levou a entender a despersonalização como parte do processo de transformação de um saber a ensinar e a comparação dos documentos nos levou a verificar no corpus que o recurso linguístico de apagamento desvelava a dimensão política da TD.

O procedimento de comparação dos documentos nos levou a contatar que nas OCEM não há nenhuma citação de autores e nos RCEM-PB encontram-se 9 (nove) citações de vários pesquisadores acadêmicos ${ }^{6}$, porém, dentre esses não figura nenhuma referência a Geraldi, o articulador e divulgador dessa proposta. Logo, manifesta-se nessa comparação o apagamento e sua contraparte - a pulverização -, pois, ao mesmo tempo que ao articulador metodológico e divulgador da proposta não é citado e vários outros o são, inclusive colaboradores e continuadores de sua obra, manifesta-se a pulverização que faz com que o leitor leigo não saiba a quem atribuir a autoria da proposta. A título de exemplo, se compararmos esse procedimento com os exemplos da física já apresentados, concluiremos qual deles permite a construção de referência sobre a propositura.

Uma ideia, um conceito, uma proposta que não pertence a alguém mas, sim, a vários autores pode passar a ser de todos e pode passar a ser apresentada "à moda da casa", ou seja, segundo a ótica de quem faz a apresentação. Num sentido extremo, designação e conceito podem não ter mais nada da a ver com a origem.

Essa pulverização de autores, por sua vez, dá ao RCEM-PB um caráter de documento que se compromete com a divulgação científica, pois, o corpo do texto está permeado de referências a vários estudiosos da área de Língua/gem que pesquisam sobre AL, conforme já mencionado. Esse compromisso nos faz pressupor que o leitor-modelo presumido é um professor-leitor que desconhece as (novas) teorias linguísticas adotadas no documento e que

\footnotetext{
${ }^{6}$ Os autores citados no documento são COSTA VAL, 2002; PCNLP, 1998; PCN+, 2002; RUIZ, 2001; BUIM, 2004; OCEM, 2006; TRAVAGLIA, 2003.
} 
gostaria ou que precisaria, posteriormente, ir até o texto-fonte para conhecê-las a fundo, mas, por outro lado, seria um leitor com intimidade com o texto acadêmico a ponto de entender marcas de citação como sugestão de leitura. Assim, ao apresentar o tema da AL, são indicadas fontes para ampliar o repertório teórico do professor, como exemplificamos na figura 1 a seguir, retirada do RCEM-PB:

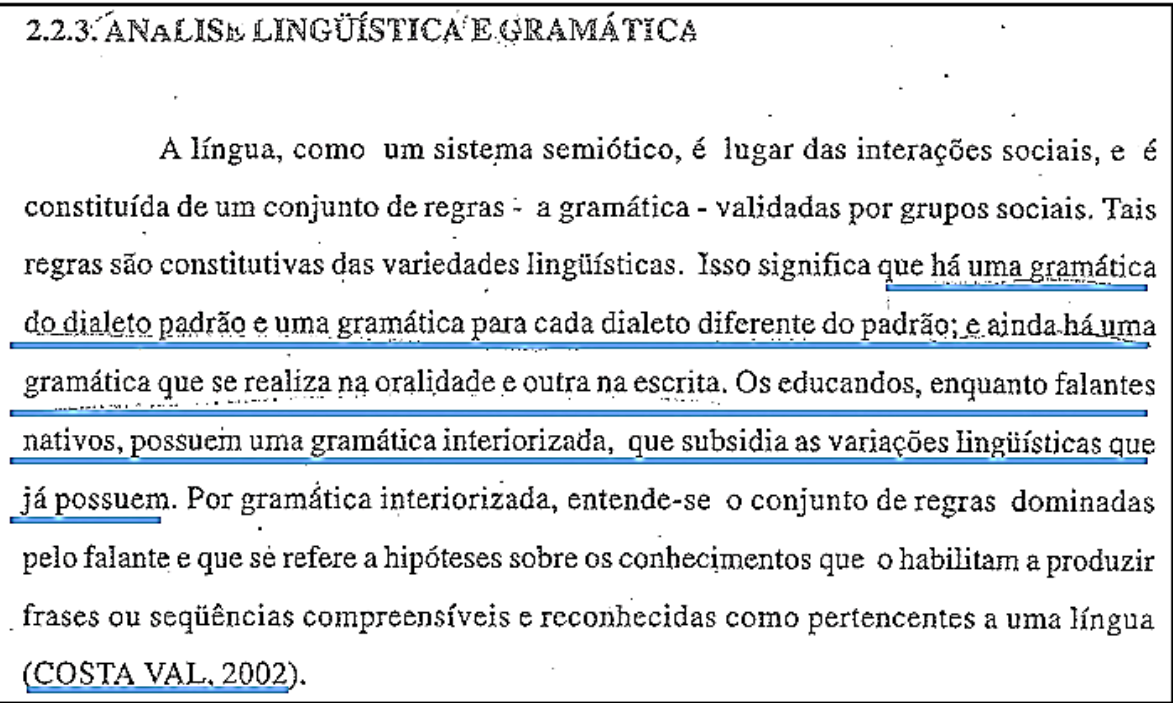

Figura 1.RCEM-PB, p. 53.

Como podemos ver, o texto segue os padrões acadêmicos de citação, apresentando ao final do trecho, entre parênteses, a fonte inspiradora ou que fora parafreseada. Esse tipo de citação tem por objetivo tanto dar credibilidade ao autor do texto em tela quanto suscitar a continuidade da leitura, a partir da recuperação da fonte. Comum aos textos acadêmicos, esse recurso pode tornar o documento parametrizador um texto com pouca legibilidade para o o professor que não está na academia, porque esse tipo de citação pode significar pouca transformação da fonte de referência. Nesse exemplo, esse comprometimento da legibilidade parece ser ainda acentuado pelo uso da terceira pessoa do singular e com partícula reflexiva, que é um recurso linguístico de distanciamento entre o autor e o leitor.

Essa articulação entre a divulgação do saber - no caso a AL - e a sugestão de busca por referências nos parece construir uma identidade de professor-leitor nos documentos, cuja definição tomamos das considerações de Nóbrega (2008). De acordo com essa autora, podemos crer que tanto a paráfrase quanto a citação direta a pesquisadores acadêmicos pressupõem um 
professor-leitor em um lugar de desatualização didática e essa menção faz crer ao leitor que o saber veio de outra fonte - noosfera - , que é tacitamente tida como importante.

Dando continuidade à análise de dados, vemos que se por um lado há citações nos moldes acadêmicos, por outro, conforme anunciamos, há o apagamento de um importante autor da divulgação da AL na sala de aula, que é Geraldi. Nesse caso, mais que um apagamento, vemos um deslocamento de autoria, que passa de uma pessoa física, um pesquisador, para uma pessoa jurídica, o Estado, sendo este representado, através de três outros documentos: o PCNLP, o PCN+ (BRASIL 2002), e a própria OCEM, aqui analisada. O primeiro desses documentos é colocado como o proponente de um dos princípios essenciais à realização da $\mathrm{AL}$, conforme podemos visualizar no destaque da figura 2 relativa à menção das atividades de linguagem:

É condição indispensável para a prática efetiva de análise e reflexão lingüística a observação de dois tipos de atividades sobre a língua e seu funcionamento - cpilingüísticas e metalingúísticas -, como recomendamoṣ Parâmetros Curriculares do Ensino Fundamental (1998).

Quadro 1-Atividades epilinguísticas e metalingüisticas

\begin{tabular}{|c|c|}
\hline 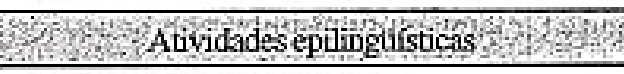 & 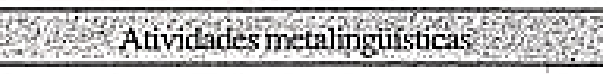 \\
\hline 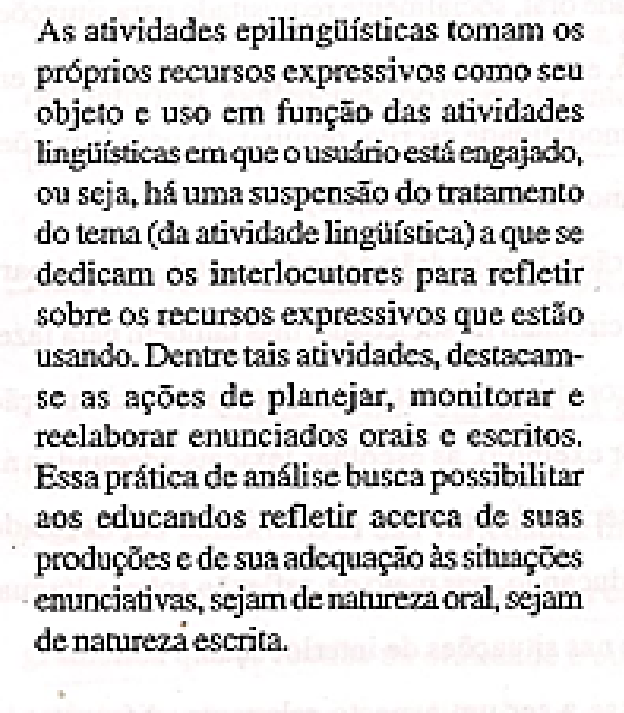 & $\begin{array}{l}\text { Jáas atividades metalinguísticas envolvem } \\
\text { o trabalho de observação, descrição e } \\
\text { categorização, por meio do qual se fala } \\
\text { sobre a língua e seu funcionamento, } \\
\text { construindo explicaçōes para os } \\
\text { fenômenos característicos das práticas } \\
\text { lingúistico-enunciativas. Pode-se inserir } \\
\text { nesse grupo açōes como construçāo de } \\
\text { conceitos e classificaçăo. }\end{array}$ \\
\hline
\end{tabular}

Figura 2. RCEM-PB, p. 56. 
A figura 02, acima apresentada, foi retirada da subseção "2.2.3. Análise linguística e gramática" do RCEM-PB que propõe um referencial teórico sobre um trabalho articulado entre gramática e AL, com algumas sugestões metodológicas.

Como podemos perceber no texto que antecede o quadro, os autores indicam que as atividades epilinguísticas devem anteceder as metalinguísticas, atribuindo a fonte dessa orientação basilar do trabalho de AL ao PCNLP. Citar um autor é rememorar ou enfatizar a produção acadêmica por ele realizada e, como já mencionamos, sugerir a leitura do texto de referência. No caso em pauta, referenda-se a leitura de um documento parametrizador do ensino fundamental, que na mesma proporção que reforça o aspecto solidário entre os vários documentos parametrizadores do ensino fundamental e do médio distancia os professores da fonte primária de proposição do conceito e da metodologia de trabalho com a $\mathrm{AL}$ - o livro $O$ texto na sala de aula - e demais publicações do mesmo autor que se seguiram a essa. Ao prefaciá-la, Geraldi menciona que os artigos ali produzidos são fruto de experiências de professores em suas práticas escolares, nas quais as atividades de reflexão (as epilinguísticas) são a etapa inicial do processo de ensino, antecedendo as metalinguísticas.

Citar o PCNLP como fonte de orientação didática para a definição de atividades epilinguísticas e metalinguísticas significa realizar uma escolha política, uma forma de despersonalização autor de referêneia e de dissicretização do saber, conforme prevê a teoria de Chevalard. Nessa etapa da TD, mesmo que se mantenha o nome e conceito do campo científico de referência, há a perda de autoridade sobre o saber.

Ao escolher o PCNLP como fonte de referência, revela-se a reprodução do controle simbólico, através do que Bernstein (1996) define por classificação e enquadramento fortes. No dado aqui apresentado, entendemos que há uma classificação forte pois se expressa o distanciamento, através do apagamento da fonte, entre o que é proposto no documento parametrizador e o campo de referência, ou seja, o texto produzido por Geraldi; assim aquilo que foi selecionado é intensionalmente considerado relevante pelos agentes didatizadores.

Em paralelo, de acordo com o conceito de enquadramento, verificamos que, este, no RCEM-PB, caracteriza-se também como forte, pois, como se trata de documento dirigido ao professor para (re)orientar as práticas pedagógicas, fica estabelecido, pela caracterização de desatualização didática, suposta e tacitamente imputada ao docente, que o transmissor (o Estado) é o único regulador do conteúdo. Portanto, referenciar os PCNLP (produzido pelo 
sistema federal de ensino, ou seja, por agentes didatizadores) como propositores do conceito e da metodologia reflexiva vinculada à $\mathrm{AL}$ é demonstrar que a instância MEC, ao selecionar, condensar e reelaborar os saberes que julga necessários, controla o que deve ser exposto, de acordo com seus interesses que se tornam, possivelmente, interesses comuns dos professoresleitores, inclusive daqueles que ainda defendiam um ensino tradicional.

Sabemos também que a natureza do documento enquanto um currículo potencialmente aberto, pois se denomina Referenciais Curriculares, não se caracteriza como um documento a ser implementado, mas se apresenta como uma sugestão/orientação/ proposição que busca se aproximar de um caráter pedagógico, de um "dizer-como-fazer" para alcançar o objetivo de melhoria na educação. Essa condição dá ao professor a possibilidade de segui-lo ou não.

Porém, tanto o PCNLP, quanto a OCEM, já reeditada em função de outras publicações para o EM (PCN, PCN+ e a primeira OCEM de 20047 ), ao serem organizados pelo governo federal, têm, num primeiro momento, uma "força de lei" sobre)a Nação, pois servem como norteadores da (re)organização do ensino que supostamente estava desarticulado, defasado, atrasado. E essa força também é assumida pelos documentos estaduais, tanto porque são produzidos a partir dos nacionais como pelo fato de serem também os primeiros documentos surgidos nesse contexto de atualização do ensino.

Embora o documento sugira que o professor-leitor está desatualizado, entendemos que esse é um estado, característico da fase de sobreposição de paradigmas, e não uma condição definitiva. Assim, mencionar a fonte de referência, nos termos de Chevallard, ou o campo de produção intelectual como define Bernstein, é indicar ao professor-leitor a fonte de referência, para compreensão e atualização, e por consequência, a ampliação da autonomia didática. Nessa perspectiva, tem relevo a ideia de que para atingir tal autonomia o professor precisa passar por uma atualização teórica e metodológica para que seja possível articulá-la à prática. $\mathrm{O}$ documento reforça, então, uma habilidade muito apreciada num âmbito de uma política Neoliberal que é a autonomia, no caso autonomia didática.

Nessa proposta política, a autonomia caracteriza-se pela mínima responsabilidade do Estado, que transfere do global para o local a "possibilidade" de serem feitas as escolhas necessárias dentre aquilo que está sendo por ele proposto, a fim de que o projeto seja executado

\footnotetext{
${ }^{7}$ Ver nas referências Brasil, 2004.
} 
a contento em função das realidades locais e das exigências globais. Ou seja, dentro do que é possível na escola a partir do que o Estado diz que pode e deve ser feito.

Alcançar essa autonomia didática exigirá do professor-leitor a participação em formações continuadas, a busca por outras leituras, além das realizadas para planejamento das atividades docentes diárias. Infelizmente, sabemos que a prática docente tem exigido cada vez mais do professor e lhe proporcionado cada vez menos condições para que ela se efetive a contento. Ainda que o Estado assuma e direcione a atualização didática, poucos profissionais conseguirão alcançá-la; será preciso o professor reconheça o lugar e a identidade que lhe estão sendo imputados e faça um grande esforço para reconstruí-los.

Prosseguindo com a análise da dimensão política da Transposição didática, manifesta pelo apagamento da fonte primária de referência sobre a proposta da $A L$, vemos que a despersonalização nos dados analisados mostra-se também através da atribuição de uma autoria coletiva aos documentos parametrizadores do ensino. No caso, os agentes didatizadores são os autores do documentos. Ambas as funções são indissociadas e as identidades mantidas no anonimato na apresentação dos documentos, como se pode ver a seguir nas figuras 3 e 4 :

A elaboração das reflexões que o Ministério da Educação traz aos professores iniciou em 2004. Desde então, definiu-se um encaminhamento de trabalho que garantisse a articulação de representações da universidade, das Secretarias Estaduais de Educação e dos professores para alcançar uma produção final que respondesse a necessidades reais da relação de ensino e aprendizagem.

Figura 3. OCEM, 2006, Seção “Apresentação”, p. 08.

Para discussão e construção desses Referenciais, foi constituído um grupo multidisciplinar de profissionais representantes da escola pública estadual de ensino médio, por região de ensino e por disciplina, e de profissionais representantes do ensino público de nível superior - Universidade Estadual da Paraíba - UEPB, Universidade Federal da Paraíba - UFPB e Universidade Federal de Campina Grande - UFCG. O trabalho desenvolveu-se por meio de seis seminários regionais, para discussão dos princípios norteadores da proposta; de oficinas para produção de material; e de reuniões para avaliação, planejamento e revisão dos textos, tendo em vista o alcance de um produto final que contemplasse necessidades reais de ensino e de aprendizagem de cada disciplina do currículo.

Figura 4. RCEM-PB, 2007, seção “Carta ao professor”, p. 11. 
Conforme visualizamos nas figuras, retiradas das seções Apresentação e Carta Ao Professor, do OCEM e do RCEM-PB, respectivamente, para a elaboração de ambos os documentos, houve a organização de equipes compostas por profissionais de distintos níveis. Embora constituídas por diferentes agentes - professores, pesquisadores, gestores, editores -, a representação de autoria do trabalho final é da Secretaria de Educação, nacional e estadual, respectivamente.

Essa menção às equipes expressa que o documento foi elaborado por especialistas para atender, supostamente, às demandas da sala de aula observadas pelo governo. Na figura 03, mencionam-se representantes do contexto acadêmico e do governo, mas também professores que contribuiram descrevendo suas realidades e apontando as necessidades locais. Na figura 04, tanto há a indicação de representantes do ensino superior como professores da escola pública. Essa informação sugere romper com a classificação e enquadramento fortes, vistos anteriormente, quando da indicação do apagamento, pois a produção do discurso pedagógico oficial, sendo realizada por representantes dessas diversas esferas - escola pública, universidade e secretaria de ensino - sugere uma espécie de negociação do conhecimento que será recontextualizado/transposto para os documentos, o que caracteriza que o poder e controle são compartilhados, redefinindo-os, então, com a classificação e enquadramento fracos quanto à elaboração do documento.

Além desses elaboradores e de certa negociação/compartilhamento entre eles, os documentos contam ainda com a participação de consultores - leitores críticos ou revisores que, em geral, são especialistas aos quais cabe a palavra final, como se pudemos verificar nos dois documentos e demonstramos a seguir:

Consuitores

Jane Quintiliano Guimarães Silva

Juliana Alves Assis

Maria de Lourdes Meirelles Matencio

Leitores Críticos

Ângela Bustos Kleiman

Jacqueline Peixoto Barbosa

Luiz Antônio Marcuschi

Maria da Graça da Costa Val

Figura 5. OCEM, 2006, p.16. 
$\mathrm{Na}$ figura 5, temos a lista dos consultores e leitores críticos da OCEM, todos eles pesquisadores da área dos estudos linguísticos, segundo pode ser contatado em pesquisa na Plataforma Lattes $/ \mathrm{CNPq}^{8}$. Todos com larga experiência no ensino de língua materna, representantes de uma tradição interacionista de ensino.

No documento estadual, observa-se a lista dos integrantes da comissão de revisão, conforme apresentamos na figura 6, a seguir:

Governo do Estado da Paraíba
Secretaria de Estado da Educação e Cultura
Coordenação de Elaboração dos Referenciais
Girleide Medeiros de Almeida Monteiro
Projeto Gráfico
Lairton Geraldo Formiga Alves
Robson Xavier da Costa
Comissāo de Revisão dos Referenciais
Aucilene Alves de Morais Martins
Maria Augusta Gonçalves de Macedo Reinaldo
Maria Célia Ribeiro da Silva
Kelly Sheila Inocêncio Cosía
Rosa Maria da Silva Medeiros

Figura 6. RCEM-PB, 2007, p.06

Grande parte dos revisores listados na figura têm seu currículo lattes facilmente rastreado, o que nos possibilitou verifícar que também são pesquisadores na área de ensino de língua e de literatura vinculados a universidades públicas do estado que encomendou o documento. Isto reforça a relação indissociada entre TD e política educacional, no sentido de que às autoridades cabe tanto a tarefa de didatizar quanto a de realizar a vigilância epistemológica, pois, os atores das esferas governamentais são chamados a compor as comissões que operacionalizam a Transposição didática e recontextualizam os saberes. Não obstante essas comissões sejam integradas também por professores, a palavra final é dada por docentes do ensino superior, pesquisadores e especialistas que são os revisores, consultores e leitores críticos, numa demonstração de que os currículos, mesmo os "abertos" como as Orientações e Referenciais, são artefatos produzidos por especialistas.

Assim sendo, compreendemos que em ambos os documentos há a presença do recurso de apagamento do autor da proposta, seja porque Geraldi não é citado seja porque há citação de

\footnotetext{
${ }^{8}$ Consultado em 24 de abril de 2015.
} 
vários outros autores que trabalharam com o tema. Entendemos que o distanciamento do autor e do conceito proposto é uma etapa do processo de Transposição didática (ato de despersonalização), inclusive por ser um novo saber, reconstruído nos moldes de quem assume sua autoria.

Como dissemos, na OCEM, a didatização da AL não faz referência a autores da esfera acadêmico-científica, nem mesmo da esfera escolar; o documento assume, assim, a autoria do que é proposto. Nesse sentido, torna-se aparentemente um documento mais autoral do que o RCEM-PB, no qual há menção de autores do campo especializado, como também há a indicação de outros documentos do Estado, o PCNLP e a própria OCEM, quando trata das atividades epilinguísticas e metalinguísticas.

Desse modo, temos, de um lado, um documento autoral e, de outro, outro um documento solidário, não só por citar fontes acadêmicas, mas ter como referência outros documentos parametrizadores do ensino, o que parece ser natural em se pensando em documentos de uma mesma de atuação política.

Portanto, compreendemos que a despersonalização, através dos recursos do apagamento da fonte primária e da pulverização das fontes de referência é parte de um processo de didatização, cuja dimensão política vem à tona, conforme que procuramos sistematizar a seguir:

Quadro 1. Sistematização de evidências da despersonalização como operação política

\section{PRINCÍPIOS de AL SEGUNDO GERALDI}

A AL deve basear-se na concepção interacionista da linguagem, materializada através de enunciados em textos;

A AL assume um processo baseado no eixo da reflexão, no qual as atividades epilinguísticas devem anteceder a metalinguísticas, caracterizando um método indutivo.

Transposição Didática da AL para documentos parametrizadores Processo utilizado: despersonalização Recursos: Apagamento e Pulverização

EVIDÊNCIAS NA OCEM

Despersonalização dos conceitos expostos, pois não há citação de pesquisadores da área de língua portuguesa;

\section{Aspectos comuns:}

Princípios metodológicos da proposta de $\mathrm{AL}$;
EVIDÊNCIAS NO RCEM-PB

Despersonalização às avessas, pois não há citação a Geraldi, mas há a citação a outros pesquisadores com publicações fundamentadas nesse autor;

Autoria da proposta de AL atribuída a documento nacional representativo de um marco divisor de paradigmas de ensino, que é um produto histórico e político - o PCNLP. A exaltação do Estado como proponente da proposta da AL;

Fonte: Lino de Araújo e Sousa, 2015. 
Assim, conforme visualizamos no quadro 1, os documentos analisados apresentam roteiros diferentes de didatização. A OCEM apresenta a AL completamente despersonalizada, assume a autoria do que propõe e não faz uso citação a pesquisadores ou especialistas, muito menos ao PCNLP para legitimar a proposta veiculada. O RCEM-PB faz uma despersonalização através da pulverização de fontes, pois utiliza a citação clássica de textos acadêmicos, referindose com certa frequência a pesquisadores da área, filiados ao eixo reflexivo do ensino de língua, conforme nota 3, cujas publicações são posteriores as duas principais obras de Geraldi [1984 (2006) e 1991 (2003)] sobre o tema e nelas estão baseadas, exceto a do pesquisador estrangeiro.

Dessa forma, os dados revelam um aspecto particular que pode contribuir para a revisão das teorias aqui apresentadas. A despersonalização do saber de referência sobre AL dáse tanto pelo apagamento quanto pela pulverização. Na OCEM o processo se dá de forma absoluta, isto é, sem nenhuma referência. Já no RCEM-PB dá-se através da citação de vários autores, entre eles o próprio Estado, levando o professor-leitor a não ter certeza de quem orquestra o concerto de vozes sobre o tema. Nesse sentido, entedemos que o pulverizado é também despersonalizado.

Portanto, conforme a teoria de Chevallard, a despersonalização aparece no estudo em tela como caracterizadora da transformação do saber. Tal processo pode ser visto à luz da Recontextualização Didática como um processo político uma vez que há o enquadramento fraco (controle), pela não citação de um dado autor e a citação de vários outros, seus continuadores. Ao mesmo tempo em que há uma classificação forte (poder), dado que a proposta da AL é referida como tributária de outros documentos parametrizadores PCNLP, PCN+ e OCEM e de vários outros autores. Nesse sentido, (re)apresentá-la é fortalecer o poder sobre um dado conteúdo, conceito e metodologia selecionados pelo Estado, cujos documentos são solidários entre si.

\section{Considerações finais}

O objetivo deste artigo foi o de demonstrar a dimensão política dos processos de Transposição e de Recontextualização didática do conceito e da proposta metodológica do ensino de AL. O trabalho parte do princípio de que essa dimensão é intresseca a esse processo e nos dados analisados expressa-se a partir do recurso apagamento da fonte primária de referência sobre o tema e da citação de várias fontes secundárias baseadas nessa primeira. 
Esse recurso remonta ao processo de despersonalização próprio da TD, conforme previsto por Chevallard. Os dados levaram-nos a identificar uma despersonalização pulverizada, no sentido de que ao mesmo tempo que a fonte primária não é referida fontes secundárias o são, dentre essas documentos do Estado. Essa despersonalização parece implicar em dois aspectos. O primeiro está relacionado a necessidade de legitimação do documento estadual num nível de ensino em que documentos federais anteriores não tinham se firmado (BRASIL 2000, 2002 e 2004). Assim, a construção mais próxima de um texto acadêmico, permeado de referências, parece ter sido a alternativa encontrada para tal. O segundo aspecto foi que denominamos de documento solidário por fazer referência explícita aøs PCNLP, ao $\mathrm{PCN}+$ e a OCEM. As referências a esses outros documentos são tanto um recurso de argumentação por autoridade como um recurso de expressão de uma similitude, (re)apresentando conceitos já postos. Isso se mostra, por exemplo, na referência ao PCNLP ao tratar das atividades epilinguísticas e metalinguísticas, como também no início da subseção sobre produção, referir-se a OCEM para elucidar atividades possíveis.

O processo de despersonalização nos documentos analisados resulta no que denominamos anteriormente de enquadramento fraco e classificação forte. Essa correlação de forças leva ao que entendemos como uma exaltação do Estado, que é colocado como um instrumentalizador didático-pedagógico, pois, selecionou, organizou e divulgou aspectos sobre o conceito e o método adequados a um ensino reflexivo de língua, materializados nas publicações do PCNLP, PCN+. Dizer isto com as categorias da teoria de Bernstein significa que o Estado selecionou, simplificou, condensou e reelaborou o saber sobre ensino de língua. Essa condição de instrumentalizador é marcada, linguisticamente, através da menção a essas publicações oficiais, cujas propostas já foram executadas, avaliadas e publicadas, ou seja, estão nesses novos documentos - OCEM e RCEM-PB - porque já se revelaram positivas e por eles são legitimadas; exaltam, assim, o trabalho do Estado.

Isto posto, podemos concluir que a dimensão política de um processo de Transposição didática parece ir além do uso de um recurso de apagamento. Conforme procuramos demonstrar não é apenas pelo que foi apagado, mas pelo que ficou inscrito (ainda que pulverizado) que essa dimensão se revela constitutiva da TD e influenciadora das outras duas dimensões - a pedagógica e a linguística. 


\section{Referências bibliográficas}

BRASIL, Ministério da Educação e cultura. Secretaria de educação básica. Parâmetros curriculares para o ensino médio. Brasília: MEC/SEB. 2000. (Linguagens: códigos e suas tecnologias). Disponível em http://portal.mec.gov.br/seb/arquivos/pdf/blegais.pdf. Acesso em 20 março 2014.

BRASIL, Ministério da Educação e do Desporto. Secretaria de educação básica. Orientações curriculares para o ensino médio. Brasília: MEC/SEB. 2004. (Linguagens:códigos e suas tecnologias). Disponível em http://portal.mec.gov.br/seb/arquivos/pdf/02Linguagens.pdf. Acesso em 20 agosto 2015.

BRASIL, Ministério da Educação e do Desporto. Secretaria de educação básica. Orientações curriculares para o ensino médio; volume 1. Brasília: MEC/SEB. 2006. (Linguagens:códigos e suas tecnologias).

BRASIL. Ministério da Educação e Cultura. PCN+ ensino médio: orientações educacionais complementares aos Parâmetros Curriculares Nacionais. Brasília: MEC/SEMTEC, 2002. (Linguagens: códigos e suas tecnologias).

BRASIL. Parâmetros Curriculares Nacionais: Língua Portuguesa. ( $3^{\circ}$ e $4^{\circ}$ ciclos do ensino fundamental). $\quad$ Brasília: $\quad$ MEC, $1998 . \quad$ Disponível em http://portal.mec.gov.br/seb/arquivos/pdf/portugues.pdf. Acesso em: dez 2014.

CHEVALLARD, Y. La Transposition Didactique. Du savoir savant au savoir enseigné. Grenoble: La Pensée Sauvage, 1991. 126 p.

GERALDI, J. W. et al. (orgs.). O texto na sala de aula. 4. ed. São Paulo: Ática, [1984]2006. $136 \mathrm{p}$.

GERALDI, J. W. Portos de passagem. 4. ed. São Paulo: Martins Fontes, [1991]2003. 288 p.

. Linguagem e ensino: exercícios de militância e divulgação. Campinas: ALB \& Mercado de Letras, 1996.150 p.

A aula como acontecimento. São Carlos. Pedro \& João, Editores. 2010. 208 p.

LAPERRIÈRE, A. Os critérios de cientificidade dos métodos qualitativos. POUPART, J. et al. A pesquisa qualitativa: enfoques epistemológicos e metodológicos. Petrópolis: vozes, 2012. p. $410-436$.

LE GOFF, J. Documento-monumento. História e memória. Tradução Bernardo Leitão (et al). 4. ed. Campinas, São Paulo: Editora da UNICAMP, 1997, p. 525 - 539.

LEITE, M. S. Recontextualização e Transposição Didática: Introdução à Leitura de Basil Bernstein e Yves Chevallard. São Paulo: JUNQUEIRA \& MARIN, 2007. 96 p. 
MAINARDES, J.;STREMEL, S. A teoria de Basil Bernstein e algumas de suas contribuições para as pesquisas sobre políticas educacionais e curriculares. Revista Teias, n. 22, v. 11, p. 01 - 24.2010 .2 Disponível em http://periodicos.proped.pro.br/index.php/revistateias/article/viewFile/575/580. Acesso em 10 maio 2014.

MOITA LOPES, L. P. da (Org.). Linguística Aplicada na modernidade recente: festischriff para Antonieta Celani. São Paulo: Parábola, 2013. 288p.

MOITA LOPES, L. P. da (Org.). Por uma linguística aplicada indisciplinar. São Paulo: Parábola, 2006. 280p.

MOREIRA, H; CALEFFE, L. G. Metodologia da pesquisa para o professor pesquisador. Rio de Janeiro: DP\&A, 2008. 248 p.

NÓBREGA, G. S. Manual do professor de língua portuguesa: da caracterização do gênero à leitura dos professores. Campina Grande, 2008. 227 p. Dissertação (Mestrado em Linguística Aplicada). Centro de Humanidades, Universidade Federal de Campina Grande, Campina Grande, 2008.2 Disponível em http://www.ual.ufcg.edu.br/posle/index.php/Disserta\%C3\%A7\%C3\%B5es. Acesso em: ago 2015.

PARAÍBA. SECRETARIA DE EDUCAÇÃO E CULTURA. Referenciais curriculares para o ensino médio do estado da Paraíba. João Pessoa. SEC, 2006.

PETITJEAN, A. Importância e limites da noção de Transposição didática para o ensino do francês. Fórum Lingüístico. Tradução de: Ana Paula Guedes (Universidade Estadual de Maringá - UEM) e Zélia Anita Viviani (Universidade Federal de Santa Catarina - UFSC), n. 02, v. $05, \quad$ p. $83-116$, jul/ dez. 2008. Disponível em: http://www.periodicos.ufse.br/index.php/forum/article/view/10805/11032.

RAFAEL, E. L. Construção dos conceitos de texto e coesão textual: da linguística à sala de aula. São Paulo, 2001. 219 p. Tese (Doutorado em Linguística Aplicada). Instituto de Estudos da Linguagem, Universidade Estadual de Campinas, São Paulo, 2001. Disponível em: http://www.bibliotecadigital.unicamp.br/document/?code=vtls000219369. Acesso em: mar 2014.

SANTOS, E. C. dos. O processo de Transposição didática no jornal e na escola. Campina Grande, 2009. 227p. Dissertação (Mestrado em Linguística Aplicada). Centro de Humanidades, Universidade Federal de Campina Grande, Campina Grande, 2009. Disponível em http://www.ual.ufcg.edu.br/posle/index.php/Disserta\%C3\%A7\%C3\%B5es. Acesso em: ago 2015.

SOUSA, I. G. da S. Do advento à proposta: Transposição didática da análise linguística em documentos parametrizadores do ensino médio. Dissertação (Mestrado em linguística Aplicada). Centro de Humanidades, Univversidade Federal de Campina Grande, Campina Grande, 2015. 


\section{Bibliografia}

BERNSTEIN, B. Class, codes and control: The structuring of the pedagogic discourse. London: Routledge, 1990. crossref http://dx.doi.org/10.4324/9780203011263

Class, codes and control: theoretical studies towards Sociology of Language. London:

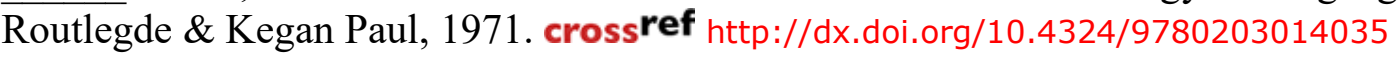

Class, codes and control: theoretical studies towards Sociology of Language. London: Routlegde \& Kegan Paul, 1973.

Class, codes and control: toward a theory of educational transmissions. London: Routledge \& Kegan Paul, 1975. crossref http://dx.doi.org/10.4324/9780203011430

Pedagogía, control simbólico e identidad: teoria, investigación y crítica. Madrid: Ediciones Morata, 1998.

Pedagogicy, Simbolic control and identidy: teory, research and critic. London: Rowman and Littlefield, 2000.

BUIN, E. A gramática a serviço do desenvolvimento da escrita. Revista Brasileira de Linguística Aplicada, v. 4, n. 1, p. 155-171. 2004. Disponível em http://www.scielo.br/scielo.php?pid=S1984-63982004000100009\&script=sci arttext. Acesso em 10 novembro 2014.

COSTA VAL, M. das G. A Gramática do texto, no texto. Revista de Estudos Lingüísticos, Belo Horizonte, n. 02, v. 10, p.107-133, julho/dezembro. 2002. Disponível em http://periodicos.letras.ufmg.br/index.php/relin/article/view/2339. Acesso em 20 fevereiro 2013.

RUIZ, E. Como se corrige redação na escola. Campinas: Mercado das Letras, 2001. 247 p.

TRAVAGLIA, L. C. Gramática e interação: uma proposta para o ensino de gramática. São Paulo: Cortez, 2003. 245 p. 